\title{
Data Analysis on the Irrationality Behind Consumption and Investment Behaviors
}

\author{
Jijun Liang ${ }^{1, *}$ \\ ${ }^{1}$ James Cook University Singapore, Singapore, 380051 \\ *Corresponding author. Email: shilishuang@cas-harbour.org
}

\begin{abstract}
There is an assumption in Economics: people are rational. While, what behavioral economics emphasizes is that human behaviors are irrational. Based on the theories of behavioral economics, this paper analyzes practical cases and data, draws the conclusion that people are irrational many times in their daily lives. This paper intends to explore the elements leading to irrational consumption and investments, and provides conservative suggestions on avoiding such irrational behaviors.
\end{abstract}

Keywords: behavioral economics, irrational, decision making, investment

\section{INTRODUCTION}

People usually feel that they are rational, but they often act irrationally when they get hot. For example, some people clearly do not have a credit card yet, and often buy a costly item on impulse; another example, some people know that the chances of winning the lottery are meager, and they still spend much money on the lottery every year, then hope they get rich overnight. Not only ordinary people but celebrities often act irrationally. For example, the respected human rights leader Martin Luther King maintains an extramarital relationship with many women [1]. The explanation given by behavioral economists for these incredible decisions is that because the human brain itself is defective, it has many inherent cognitive biases, so people often make wrong decisions.

Therefore, some people may think that behavioral economics overthrows all economics, but this thinking is wrong. For example, scientists worldwide know that temperature will not last forever, which means that people will not always be in a rational state. However, many experiments conducted by scientists must conduct research and draw conclusions under the premise that the temperature or atmospheric pressure remains unchanged. This is a typical "Laboratory Situation"- to make experiments scientific, you must have a series of assumptions, and the assumptions are more straightforward than the real world. Otherwise, thousands of factors in the real world must be considered. In this way, it will not simplify the experiment and make any reasoning and draw any simple conclusions [2]. It is not that behavioral economists discovered irrational human behaviors, but that people have always quantified these irrational human behaviors in the past, ignoring how thousands of factors in the real world affect each other. Therefore, behavioral economics is not so much overthrowing all economics as it is a supplement to economics. This thesis will study the irrational side of people in daily life and the psychology behind the irrationality and explore how people's thinking about interests affects economic decision-making through behavioral economics.

\section{ECONOMIC RATIONALITY}

\subsection{Maximize the profit}

When it comes to the rationality of economics, people may immediately think of a lot of mathematics or some very detailed knowledge related to money, but that is not the case. If economics is peeled off layer by layer like an onion, its innermost and core connotation discusses human behavior. It talks about what kind of behavior a person will make when facing a stakeholder to gain more incredible benefits. And when many people face the stakes, what type of behavior they will do with each other, and what kind of mutual influence will these behaviors have. The knowledge to study these things is behavioral economics. For example, supposing that a person walks to a restaurant today, and there are 
only two items sold in the restaurant: chicken chop and steak, both of which are sold for $\$ 10$. This person is hungry, and he wants to eat a piece of meat to fill his stomach. Which one would he buy? Or assume that if he is a person who does not eat chicken at all, then, of course, he will buy the steak. This is called rationality. The rationality of economics means that rational people will choose options that maximize their interests.

Similarly, he must pay 10 dollars. If a person who does not eat chicken, the value of chicken chop to him is zero. The only steak is valuable to him, so of course, he will choose steak because that is a profitable maximization.

\subsection{Personal preference}

Let us give another example. Suppose a woman who thinks that Coke, Sprite, and Fanta are almost delicious today and goes to a convenience store. Coke, Sprite, and Fanta for her to choose from, and they all sell the same, 1 US dollar, she will suddenly not know what to choose because the three drinks are all the same value to her, and she will not be treated differently in her eyes, so she will have difficulty in choosing. This is also rational. The so-called rational behavior in economics is nonsense most of the time. What each of us does every day is very rational in many cases. If people want to spend the same amount of money, of course, they will buy their favorite things. If the same thing and the same price, of course, people will not know how to choose. These are all rational. But don't underestimate the word rationality. In economics, the word rationality has an essential meaning. Almost all economic theories revolve around the word rationality. And economics has a massive assumption. It assumes that all people in the world are rational when they engage in economic behavior, especially when facing money-related matters. Most people are rational. Even though occasionally there may be a little irrational due to miscalculations, they are all small mistakes.

\subsection{Brain calculation}

When a question is asked and an answer needs to be given immediately, the answer given by many people is expressed through intuition instead of careful thinking of the brain. The human brain is divided into cerebrum and cerebellum, and the cerebellum is multifunctional [3]. The multi-function of the cerebellum can be understood in this way. For example, while seeing a beautiful woman, a man may calculate that this woman is walking towards him and he may also calculate the speed of walking, so he will dodge left and right, at the same time he may be doing these things, this is the Parallel Walk Sensing of the cerebellum rather than the subconscious, because the subconscious is a suppressed thought. From the macro perspective, the subconscious is that a person can only do one thing at a certain time, so when there is more than one thing a person needs to deal with, he may choose to stop other things. Just like when a person is driving, he cannot drive while watching TV series. He is only switching between driving and watching TV series. So, in fact, he is using his brain to control his behavior. When facing ordinary things, people will only rely on their own experience or shortcuts to make judgments instead of slowly thinking because they do not have time. Just like if a tiger suddenly appears in front of a man, he will not spend a few minutes thinking about how big the tiger is, what kind of tiger is, and how aggressive it is before he escapes, but through his shortcut. He is judging to choose to escape immediately. Usually, this kind of shortcut is correct, so it might not suit people to follow the shortcut when facing some small things. However, when faced with some big things and big moments that people need to take seriously, they need to clear their prejudice and use critical thinking to do step by step [4]. This inference is rational thinking, and in fact, monkeys first invented it. To track female monkeys, male monkeys jump in three-dimensional space, and calculations in three-dimensional space require rational calculations, so people assume that this animal instinct has become anthropic rational deliberation tool. This is the origin of brain calculations [5].

\section{IRRATIONAL THINKING}

\subsection{Past understanding}

Human irrational thinking has been the fact that everyone knows since Plato. In the past, when people discovered some irrational behaviors, they would use other theories and hypotheses to explain these behaviors, that is, use the premise element of "when in a certain situation" to rationalize the irrational behaviors. Explain the fundamental economics and let economics be accompanied by endless calculations [6]. It is also said that the financial results made by people due to irrationality are consistent with the results determined by rationality. This statement is also inaccurate. For example, a company plans to open gas stations in deserts, grasslands, and highways. Everyone might take it for granted at the beginning that the gas station on the highway must be the best business, and the business on the desert must be bleak. However, after a year of operating a gas station, the most irrational result is not the result of rational speculation.

\subsection{Example of irrationality}

People will choose to maximize their interests, this is rationality. Supposing that there are two kinds of coupons in a supermarket, one is 10 dollars, and the other is 50 dollars. People can take any coupons in the supermarket without paying any price or returning them 
to the supermarket. So, people will take the 50-dollar one.

Nevertheless, behavioral economics tells people that many people think that most people will choose options that maximize their benefits when facing economic decisions, but they are not. For example, supposing that a person holds two 50-dollar coupons in his hand. If he thinks that the two are the same precious, then he is a very rational person. Because a reasonable person would think that any one of them is 50 dollars, and 50 dollars can only buy things worth 50 dollars, and its purchasing power is 50 dollars. So, these two coupons are the same thing to him because the goods and services they can exchange for him are the same. This is nonsense of economic rationality. However, many people may not believe that many of the two 50-dollar coupons that people hold in their hands, one is more precious and the other is less precious. This sounds very irrational, but in real life, people do it. Suppose one is a person's salary for a day, and the other is won by playing poker. At this time, most people will think these two are not the same precious. They will feel that the coupon they won from playing poker can be spent casually, and the salary they get from working hard should be used well. This is irrational.

Some people may say that salaries are hard-earned, and the money to win playing poker is extra. There is no such thing as extra because when these two coupons are replaced with electronic coupons when both become numbers on the mobile phone, there will be no difference between them. So, these two 50-dollar coupons are precisely the same thing to him, but because of what happened in the past, people's judgments on the value of the two are different. This is one of the most common irrational behaviors committed by humans. However, most people like this, so there is no right or wrong question for irrationality. Rationality and irrationality do not mean right or wrong. If people can look at such things more rationally, they can be more efficient in wealth management. The simplest thing is that if you can get money in various ways, no matter how you get it, treat them as essential and cherish them, save them well, and manage them well, people will have a more comprehensive view. Wealth management will improve management efficiency, and wealth accumulation will undoubtedly be faster than before. This is called beating the market.

\section{IRRATIONAL INVESTMENT BEHAVIOR}

\subsection{Behavioral Economics}

Regarding behavioral economics, people may think it is very esoteric, but there is an ancient story in China that has involved behavioral economics. This story is "Zhao San Mu Si". The story is about a monkey who said that they only have three fruits in the morning and four fruits in the evening, which seems very few. Then the host told them that it is better to change to four fruits in the morning and three fruits in the evening. The monkeys felt very good after hearing this [7]. Thus, the illusion of monkeys can also be regarded as behavioral economics.

Behavioral economics uses so many experiments because behavioral economics is heavily influenced by psychology, and experiments have a long history in psychology. So, when the category of behavioral economics emerges, it is natural to learn from the experience of psychology and adopt experiments. Today, even if it is not behavioral economics, traditional economics often uses experiments, an accepted method.

\subsection{Return on investment in stocks and MPF (Hong Kong)}

Mandatory Provident Fund Schemes (MPF) is a retirement security program enacted by the British Hong Kong Government on July 27, 1995, via the "Mandatory Provident Fund Schemes Ordinance" and officially implemented on December 1, 2000. Except for a limited number of persons, Hong Kong employees aged 18 to 65 are required to join the MPF program [8].

Most people in Hong Kong put most of their MPF funds in the option of preserving capital, such as $50 \%$ stocks and $50 \%$ bonds, which are relatively conservative MPF investments. There are tricks in this evenly distributed strategy [9]. It is relatively simple for Hong Kong, because in the United States if it is a retirement fund, like Hong Kong's MPF, there are often more than a hundred types of funds to choose from, so it is not easy to choose [10], but in Hong Kong, there are usually only ten choices. Therefore, in Hong Kong, people are relatively easy to choose from. This is a framing effect. When people think about how many choices they will receive, if one hundred choices are given, people may even account for one percent of each, which will affect their choices because of that number. There is an experiment. If there are more than a dozen options for the same item in a supermarket, fewer items will be sold because people with difficult choices will choose not to buy. However, if a supermarket only puts a few, and each has a notable tendency, as long as the customer knows what that tendency is, it is easy to choose and buy, and the sales will be more in the end [11]. Going back to the question of buying bonds just now, since so many people in Hong Kong choose to put a considerable part of their retirement funds in the capital preservation fund, it is commonly believed that they must feel that this can help them reduce their risks to a considerable extent. The MPF cannot be used immediately. Although the community is now discussing whether people can borrow to buy a flat in 
the future, the MPF is still to make calculations decades later, so this is a long-term investment. As a long-term investment, the return gap between stocks and capital preservation options has been controversial. It can be imagined that if you buy the Tracker Fund in Hong Kong's Hang Seng Index and hold it for ten years, that is, sell it after ten years, the average monthly return will be about zero to two percent, multiplied by twelve months means a $12 \%$ return every year. Furthermore, everyone knows that one-month fixed deposit interest is a low-interest rate, but occasionally there will be minor ups and downs, and the interest rate may be higher in some years.

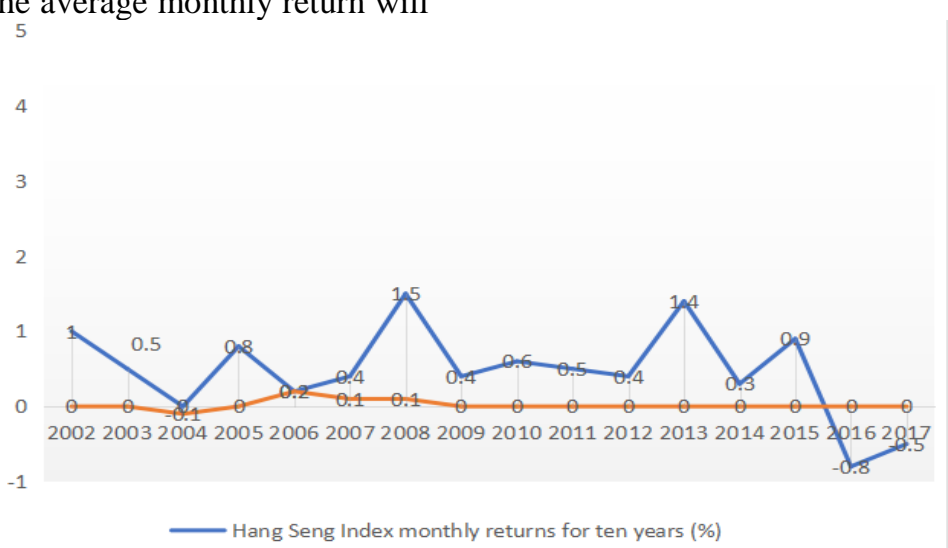

Figure 1. Long-term comparison of Hang Seng Index interest and fixed deposit interest [11]

However, the interest rate of Tracker Funds in the Hang Seng Index has been at a high level for an extended period, as shown in Figure 1.

At this time, if a traditional explanation is introduced: stocks have a risk premium, and whether this premium is sufficient to explain the difference between stocks and regular returns because stocks always rise and fall. Although the average return is slightly higher, many people may be reluctant to take risks for a higher return. So, economists have calculated as early as 20 years ago. Generally speaking, it is difficult for people to explain why they still decide not to buy stocks when faced with a gap of $10 \%$ in a year. From the perspective of an ordinary person, every six months, the MPF will send him a letter telling him about the return. If the MPF has been accumulated for a long time, he will be heartbroken. Monthly stock performances were suddenly poor. Newspapers occasionally said that people's returns in the past ten years were only $10 \%$, and they could not even keep up with inflation. Alternatively, maybe he read an MPF return and said that he made more than 200,000 Hong Kong dollars last month, but suddenly only 60,000 left this month. It is not that people have not tried to experience a considerable fluctuation, but people have this kind of psychology, that is, even if they do not get the money back until the age of 60 , they will feel that if they put half of it on a more stable fund, will the rewards be so bad? This kind of profit and loss report every six months affects a person's choice of risk aversion. On the contrary, if they make much money, they will have this mentality. Since they have made so much money, should they put this money in a more stable place? As a result, no matter how much they earn or how little, they will want to change that combination.
As a result, the changed combination could not reach the idea of investing 100\% in the Hang Seng Index and then slowly waiting for it to increase in value. A crucial point is raised here: the money will be withdrawn after more than ten years, but the notice sent will be frightening. For example, the notice suddenly said that there was a balance of 100,000 Hong Kong dollars last year, and now there are only 20,000 Hong Kong dollars left.

Nevertheless, it is impossible to extract the ideas of rational economic people. They will find it okay, as long as they make a profit at the age of 60 . Nevertheless, an average person will feel unhappy, especially when the money is getting bigger and bigger. At first, it was only 100,000 Hong Kong dollars, but if it has now been rolled over to 500,000 Hong Kong dollars, 600,000 Hong Kong dollars, or even more than 1 million Hong Kong dollars, that number will affect the mood.

Generally, people's channels for obtaining financial information may be online, such as looking at mobile apps. The default Hang Seng Index period displayed does not show data for ten years but relatively short-term, such as about one month. The short-term Hang Seng Index returns will become exceptionally volatile, and there are many opportunities to underperform fixed deposits. They can see that MPF is all long-term investment. It receives information every six months. If they are careful, they will receive information every week or every day to see the ups and downs of the return curve. This breaks people's thinking about economics. People usually think that more information is more beneficial to investors. However, what is presented now is that the more information and psychological factors, it will lead to errors in judgment. 
In summary, the common investors are short-sighted, which in other words, it is loss aversion. Loss aversion means that when people lose a lot when they are at a low position, they feel much heartache, so they sell at a low position, but it may pick up the next day. This is the phenomenon of buying high and selling low.

\section{CONCLUSION}

It is believed that every consumer makes the decisions through rational thinking, but this is often not the case. Human rationality is fragile, and sometimes others can ultimately affect their rationality by uttering a specific sentence with a bit of a trick. Hence, in real life, each decision will be affected by the information people come into contact with around themselves, and some irrational behaviors are often made. The most effective way to change irrational thinking is to try to obtain sufficient information. This sufficient information will form an objective reference point and activate our brains to carry out meaning tests, thereby reducing the influence of external factors on persons.

\section{AUTHORS' CONTRIBUTIONS} Liang.

This paper is independently completed by Jujun

\section{ACKNOWLEDGMENTS}

I would first like to thank my professor, Nathan. Novemsky of the Yale University. No matter the content of his lectures, or his teaching methods and attitudes, he is perfect. I learned a lot about behavioral economics from his class. He can always listen and answer my questions about the subject patiently, and he can always understand and support the ideas I put forward.

I would also like to thank the experts who were involved in the validation survey for this research project: Zimeng Jia, Lulin Li, Cuihong Wang, Jiaqiong Sun. Without their passionate participation and input, the validation survey could not have been successfully conducted.

Finally, I must express my very profound gratitude to my parents and to friends for providing me with unfailing support and continuous encouragement throughout my years and study and through the process of researching and writing this thesis. This accomplishment would not have been possible without them.

\section{REFERENCES}

[1] NO COMPARISON: Broward Metro Edition. (2001). Sun-Sentinel (Fort Lauderdale, Fla.).
[2] Loeffler, S. N., Hennig, J., \& Peper, M. (2017). Psychophysiological Assessment of Social Stress in Natural and Laboratory Situations: Using the Experience Sampling Method and Additional Heart Rate Measures. Journal of Psychophysiology, 31(2), 67-77. https://doi.org/10.1027/0269-8803/a000170

[3] Wang, Y. (2017). Transient Receptor Potential Canonical Channels and Brain Diseases (1st ed. 2017.). Springer Netherlands. https://doi.org/10.1007/978-94-024-1088-4

[4] Butler-Bowdon, T. (2017). 50 psychology classics : your shortcut to the most important ideas on the mind, personality, and human nature (Second edition.). Nicholas Brealey Publishing.

[5] Fattori, P., Breveglieri, R., Marzocchi, N., Laura, P., \& Galletti, C. (2010). Monkey area V6A codes reaching movements in the three dimensional peripersonal space. Journal of Vision (Charlottesville, Va.), 5(8), 630-630. https://doi.org/10.1167/5.8.630

[6] Kelly, B. D. (2020). Looking at the facts about suicide: COMMENTARY ON... Rational and irrational suicide in Plato and modern psychiatry. BJPsych Advances, 26(4), 236-237. https://doi.org/10.1192/bja.2020.12

[7] Huang, Y. (2018). Patient Moral Relativism in the Zhuangzi. Philosophia (Ramat Gan), 46(4), 877894. https://doi.org/10.1007/s11406-018-9959-8. https://zh.wikipedia.org/wiki/Mandatory Provident Fund

[8] Chu, P. K. (2008). A study on stock-selection and market-timing performace: evidence from Hong Kong Mandatory Provident Funds (MPF). 11(4), 617-649.

[9] van der Zwan, N. (2017). Financialisation and the Pension System: Lessons from the United States and the Netherlands. Journal of Modern European History, 15(4), 554-584. https://doi.org/10.17104/1611-8944-2017-4-554

[10] Nisbet, E. C., Hart, P. S., Myers, T., \& Ellithorpe, M. (2013). Attitude Change in Competitive Framing Environments? Open-/Closed-Mindedness, Framing Effects, and Climate Change. Journal of Communication, 63(4), 766-785. 